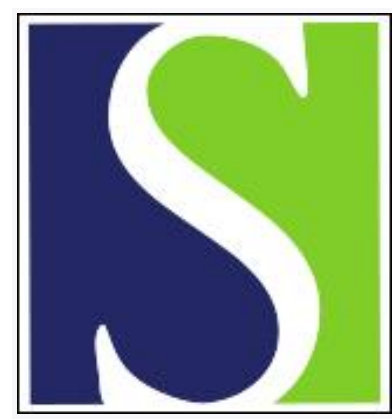

Scand J Work Environ Health 2012;38(4):337-342

https://doi.org/10.5271/sjweh.3297

Published online: 16 Apr 2012, Issue date: 01 Jul 2012

Retrospective cohort study of the risk of impaired glucose tolerance among shift workers

by Oyama I, Kubo T, Fujino Y, Kadowaki K, Kunimoto M, Shirane K, Tabata H, Sabanai K, Nakamura T, Matsuda S

Affiliation: Department of Public Health, University of Occupational and Environmental Health, 1-1 Iseigaoka, Yahatanishi-ku, Kitakyushu, Fukuoka, 807-8555, Japan. kubo@med.uoeh-u.ac.jp

Refers to the following texts of the Journal: 2005;31(3):179-183 2005;31(1):30-35

The following articles refer to this text: 2012;38(4):291-297; 2015;41(6):569-578

Key terms: cohort study; glucose; glucose metabolism disorder; historical cohort study; impaired glucose tolerance; Japan; retrospective cohort study; retrospective study; shift work; shift worker; work schedule tolerance

This article in PubMed: www.ncbi.nlm.nih.gov/pubmed/22508500 


\title{
Retrospective cohort study of the risk of impaired glucose tolerance among shift workers
}

\author{
by Ichiro Oyama, MD, ${ }^{1}$ Tatsuhiko Kubo, PhD, ${ }^{2}$ Yoshihisa Fujino, PhD, ${ }^{2}$ Koji Kadowaki, MD, ${ }^{3}$ Masamizu \\ Kunimoto, MD, ${ }^{3}$ Kiyoyumi Shirane, MD, ${ }^{3}$ Hidetoshi Tabata, MD, ${ }^{3}$ Ken Sabanai, PhD, ${ }^{3}$ Takehiro Nakamura, \\ $M D,{ }^{4}$ Shinya Matsuda, $P h D^{2}$
}

Oyama I, Kubo T, Fujino Y, Kadowaki K, Kunimoto M, Shirane K, Tabata H, Sabanai K, Nakamura T, Matsuda S. Retrospective cohort study of the risk of impaired glucose tolerance among shift workers. Scand J Work Environ Health. 2012;38(4):337-342. doi:10.5271/sjweh.3297

\begin{abstract}
Objectives The aim of this study was to investigate the effect of shift working on the risk of developing impaired glucose tolerance (IGT).

Methods This study comprised 6413 male employees (5608 daytime workers, 512 3-shift workers and 293 2-shift workers) whose work schedules remained constant during the follow-up period (mean follow-up period 9.9 years). IGT was defined as Hemoglobin A1c $\geq 5.9 \%$. The Cox proportional hazards model was used to estimate the risk of developing IGT, after making adjustments for age, smoking, alcohol consumption, leisure-time physical activity, body mass index (BMI) and Hemoglobin A1c (HbAlc) at baseline. Analysis was additionally performed for a sub-cohort of 1625 workers with BMI of $20.0-25.0 \mathrm{~kg} / \mathrm{m}^{2}$ that did not change by $>2.0 \mathrm{~kg} / \mathrm{m}^{2}$ during the follow up period.
\end{abstract}

Results The risk of developing IGT was significantly elevated among both 3-shift workers [hazard ratio (HR) $1.78,95 \%$ confidence interval $(95 \%$ CI $) 1.49-2.14$ ] and 2-shift workers (HR 2.62, 95\% CI 2.17-3.17). Significant elevations of the risk were still observed at the additional analysis on the sub-cohort (3-shift work: HR 3.55, 95\% CI 2.02-6.25; 2-shift work: HR 4.86, 95\% CI 2.62-9.01).

Conclusions Both 2- and 3-shift workers were associated with a high risk factor of developing IGT compared to day workers. Moreover, 2-shift workers had a higher risk than 3-shift workers. The risk was observed even among workers whose body mass remained within the normal range.

Key terms glucose metabolism disorder; historical cohort study; Japan; work schedule tolerance.

Shift work is widely adopted by workplaces that need round-the-clock operations. Indeed, in the US and Europe, some $15-20 \%$ of workers are estimated to work on shift schedules, with $>2.5$ billion workers estimated to be exposed to such a work schedule (1). Because of the prevalence of shift work, it is important to assess the health impact of such work.

Several previous longitudinal studies found a consistently elevated risk of shift workers developing impaired glucose tolerance (IGT) or diabetes (2-5), although some issues require further evaluation. First, it is assumed that various types of shift schedule have different impacts on health (6), however, to our knowledge, only one of these studies investigated such differences (2). Second, shift workers are reported to be a high risk population for developing obesity (7), and previous work suggested that body weight gain caused by their work schedule is a mediator between shift working and IGT risk (3). Meanwhile, the risk of IGT among shift workers who do not become obese remains unclear.

Epidemiological studies that estimate the impact of shift work on health face several common limitations that hamper an accurate assessment. These include difficulties in exposure assessment (that is, information bias), a potential significant result bias due to the "healthy worker effect" (selection bias), and socioeco-

1 Corporate Environmental Safety Health and Quality Assurance, Asahi Kasei Corporation, Tokyo, Japan.

2 Department of Public Health, School of Medicine, University of Occupational and Environmental Health, Kitakyushu, Japan.

3 Asahi Kasei Corporation Nobeoka Office Health Care Center, Nobeoka, Japan.

4 Asahi Kasei Chemicals Mizushima Works Health Care Center, Okayama, Japan.

Correspondence to: Tatsuhiko Kubo, Department of Public Health, University of Occupational and Environmental Health, 1-1 Iseigaoka, Yahatanishi-ku, Kitakyushu, Fukuoka, 807-8555, Japan. [E-mail: kubo@med.uoeh-u.ac.jp] 
nomic gaps between daytime workers and shift workers (confounding). With regard to exposure assessment, an employee's schedule may change over time, so a precise long-term follow-up of the work schedule is rarely obtained. Concerning the bias associated with the healthy worker effect, certain aspects of an occupational health policy may allow healthy workers to be selected as shift workers to provide unhealthy shift workers the chance to move to daytime work. This may lead to underestimation of the risks to health. Finally, socioeconomic gaps such as education level or domestic finance situation between shift workers and daytime workers may confound the results. (7)

The present retrospective cohort study aimed to overcome these limitations and obtain further evidence regarding the risks for shift workers in developing IGT.

\section{Methods}

We conducted an industry-based epidemiological study based on a healthcare database system of a Japanese corporation that manufactures innovative products based on chemistry and material sciences. At this particular corporation, annual health check-up results and the work schedule of every employee have been recorded since 1981. At present, more than 26000 workers are registered in the database, which is still being updated.

The main types of shift schedule at the corporation are rotating 3- and 2-shift work. Both systems are 24-hour operations and consist of 4 teams working continuous rotating shifts, which move counterclockwise for the 3 -shift system. Workers of the 3 -shift system have 3 days off within a 9-day cycle, while 2-shift system workers have 4 days off within an 8-day cycle.

In January 2009, we extracted records of work schedules and health check-ups for 20529 male workers from the database. Analysis was restricted to 6970 male workers aged $<30$ years and who were without IGT at their first health exam. Of these, 6413 workers whose work schedules remained constant during the follow-up period were selected for further study [mean age 23.6, standard deviation (SD) 2.7 years]. Of the 6413 workers, 5608 were permanent daytime workers, 512 were permanent rotating 3-shift workers, and 293 were permanent rotating 2-shift workers.

For the purpose of this study, IGT was defined as Hemoglobin A1c (HbAlc) $\geq 5.9 \%$, which is commonly used by the participating corporation as a reference value for IGT according to the recommendation of the Japan Society of Ningen Dock (8). The HbAlc value was measured by the Japan Diabetes Society (JDS) standardized method (9).

During the follow-up time of 23.2 years (63 601 person-years in total; mean follow-up period 9.9 years), 1209 incidences of IGT were detected. Self-administered questionnaires for each employee provided information on smoking habits (never smoker, current smoker, former smoker), alcohol consumption (non-drinker, drinker), and frequency of physical activity during leisure time ( $<3$ days/week, $\geq 3$ days/week) (table 1 ).

Kaplan-Meier survival curves and the log-rank test were used to compare the risk of developing IGT between rotating shift workers and daytime workers (figure 1). We estimated hazard ratios (HR) using the Cox proportional-hazard model, adjusting for age only, as well as for age together with smoking habits, alcohol consumption, frequency of physical activity during leisure time, BMI and HbAlc at first health check-up (table 2). Missing values of lifestyle factors derived from the questionnaires were treated as an additional category for this analysis.

To exclude the effect of body weight change during the follow up and describe the risk among workers without obesity, additional analyses were performed of 6413 workers with no restriction on BMI (original cohort), 2319 subjects whose BMI was $20.0-25.0 \mathrm{~kg} / \mathrm{m}^{2}$ during the whole follow-up period (sub-cohort 1) and 1625 subjects from sub-cohort 1 whose BMI changed by $<2.0 \mathrm{~kg} /$ $\mathrm{m}^{2}$ during the whole follow-up period (sub-cohort 2). The lower limit of BMI was set because not only obesity but leanness has been identified as a risk factor for diabetes among the Japanese population (10).

Calculations were performed using Stata version 10.0 (StataCorp, College Station, TX, USA) and SPSS version 12.0 software (SPSS, Chicago, IL, USA).

\section{Ethics}

The Ethics Committee for Medical Care and Research at the University of Occupational and Environmental Health, Kitakyushu, Japan, approved this study.

\section{Results}

Table 1 shows the baseline patient characteristics according to the type of work schedule. Of the 6413 male workers, $5608(87.4 \%)$ were permanent daytime workers, $512(8.0 \%)$ were permanent rotating 3 -shift workers and $293(4.6 \%)$ were permanent rotating 2 -shift workers. Three-shift workers were significantly younger than other types of workers at their first health check-up (mean age 21.3 years for 3-shift workers versus 23.9 years and 23.0 years for daytime and 2 shift workers, respectively, $\mathrm{P}<0.001$ ).

No statistical difference was observed in mean BMI between the work schedules at the first health 
Table 1. Baseline characteristics of workers according to work schedule. [SD=standard deviation; BMI=body mass index; $\mathrm{HbA1c}=$ hemoglobin A1c]

\begin{tabular}{|c|c|c|c|c|c|c|c|c|c|c|c|c|c|}
\hline \multirow[t]{2}{*}{ Work schedule } & \multicolumn{4}{|c|}{ Day time } & \multicolumn{4}{|c|}{ Three-shift } & \multicolumn{4}{|c|}{ Two-shift } & \multirow[t]{2}{*}{ P-value } \\
\hline & $\mathrm{N}$ & Mean & $\%$ & SD & $\mathrm{N}$ & Mean & $\%$ & SD & $\mathrm{N}$ & Mean & $\%$ & SD & \\
\hline Number of subjects & 5608 & & 87.4 & & 512 & & 8.0 & & 293 & & 4.6 & & \\
\hline Person-years & 54955 & & & & 5940 & & & & 2706 & & & & \\
\hline Years of follow up & & 9.8 & & & & 11.6 & & & & 9.2 & & & \\
\hline Age (years) & & 23.9 & & 2.4 & & 21.3 & & 3.7 & & 23.0 & & 3.7 & $<0.001^{a}$ \\
\hline BMI $\left(\mathrm{kg} / \mathrm{m}^{2}\right)$ & & 22.0 & & 2.8 & & 21.8 & & 2.9 & & 22.1 & & 2.8 & 0.174 \\
\hline $\mathrm{HbA1c}(\%)$ & & 5.0 & & 0.4 & & 5.1 & & 0.4 & & 5.1 & & 0.4 & $<0.001^{a}$ \\
\hline \multicolumn{14}{|l|}{ Lifestyle factors } \\
\hline Smoking & & & & & & & & & & & & & $<0.001$ \\
\hline Current smoker & & & 44.4 & & & & 57.0 & & & & 50.9 & & \\
\hline Never smoker & & & 40.3 & & & & 29.7 & & & & 30.0 & & \\
\hline Ex-smoker & & & 13.0 & & & & 11.9 & & & & 18.4 & & \\
\hline Missing & & & 2.4 & & & & 1.4 & & & & 0.7 & & \\
\hline Alcohol drinking & & & & & & & & & & & & & $<0.001$ \\
\hline Current drinker & & & 72.0 & & & & 61.7 & & & & 69.3 & & \\
\hline Non-drinker & & & 25.6 & & & & 36.9 & & & & 30.0 & & \\
\hline Missing & & & 2.3 & & & & 1.4 & & & & 0.7 & & \\
\hline $\begin{array}{l}\text { Leisure-time physical } \\
\text { activity }\end{array}$ & & & & & & & & & & & & & $<0.001$ \\
\hline 3 days per week & & & 50.8 & & & & 53.5 & & & & 65.2 & & \\
\hline$<3$ days per week & & & 33.6 & & & & 42.6 & & & & 33.8 & & \\
\hline Missing & & & 15.6 & & & & 3.9 & & & & 1.0 & & \\
\hline
\end{tabular}

a P-values derived from analysis of variance.

b P-values derived from Chi-square test.

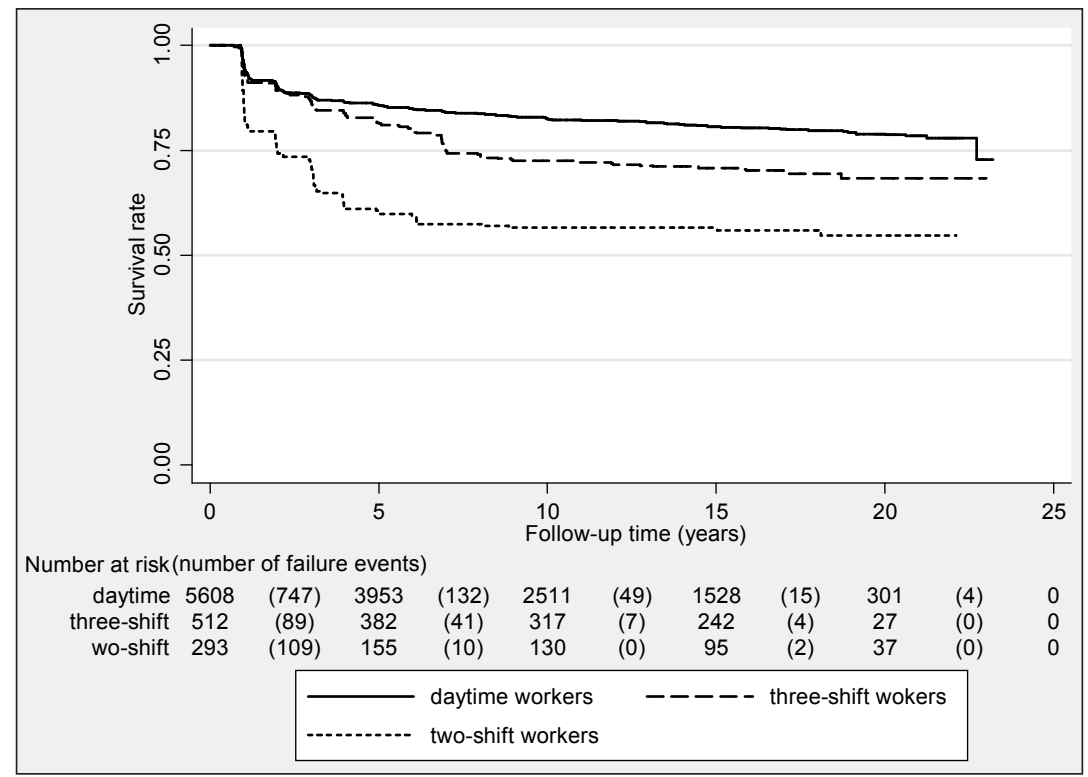

Figure 1. Kaplan-Meier survival curves for impaired glucose tolerance among workers according to type of work schedule.

check-up, but shift workers revealed a significantly higher level of HbAlc than daytime workers $(5.1 \%$ versus $5.0 \%$ for both types of shift workers versus daytime workers, respectively, $\mathrm{P}<0.001)$. Regarding lifestyle factors, smoking was significantly more prevalent among 3 -shift workers $(57.0 \%$ for 3 -shift workers, $50.9 \%$ for 2 -shift workers and $44.4 \%$ for daytime workers, $\mathrm{P}<0.001)$. Drinking was significantly less prevalent among 3 -shift workers $(61.7 \%$ versus $69.3 \%$ versus $72.0 \%$, respectively), while exercise was significantly more prevalent among 2 -shift workers (53.5\% versus $65.2 \%$ versus $50.8 \%$, respectively).

Figure 1 shows the Kaplan-Meier survival curves for IGT, demonstrating the significant between-group difference in survival rate among work schedules. Significant between-group differences were observed between day and 3 -shift work (log-rank test, $\mathrm{P}<0.001$ ), and between 3 - and 2-shift work (log-rank test, $\mathrm{P}<0.001$ ). Two-shift workers showed the lowest survival rate.

Table 2 shows the incidence rate of IGT and the 
Table 2. Incidence rate (IR) and hazard ratio (HR) of developing impaired glucose tolerance according to type of work schedule. [95\% $\mathrm{Cl}=95 \%$ confidence interval; $\mathrm{BMI}=$ body mass index; HbA1C=hemoglobin A1c]

\begin{tabular}{|c|c|c|c|c|c|c|c|c|c|c|c|}
\hline \multirow[t]{2}{*}{ Work schedule } & \multirow[t]{2}{*}{$\mathrm{N}$} & \multirow[t]{2}{*}{$\begin{array}{l}\text { Person- } \\
\text { years }\end{array}$} & \multirow[t]{2}{*}{$\begin{array}{l}\text { Number } \\
\text { of cases }\end{array}$} & \multicolumn{2}{|c|}{$\begin{array}{l}\text { Crude incidence } \\
\text { rate (per } 100 \\
\text { person-years) }\end{array}$} & \multicolumn{3}{|c|}{ Age-adjusted } & \multicolumn{3}{|c|}{ Multivariate $^{a}$} \\
\hline & & & & IR & $95 \% \mathrm{Cl}$ & $\mathrm{HR}^{\mathrm{a}}$ & $95 \% \mathrm{Cl}$ & P-value & $\mathrm{HR}$ & $95 \% \mathrm{Cl}$ & P-value \\
\hline \multicolumn{12}{|l|}{$\begin{array}{l}\text { Original cohort b } \\
(\mathrm{N}=6413)\end{array}$} \\
\hline Daytime & 5608 & 54955 & 947 & 1.7 & $1.6-1.8$ & 1.0 & & & 1.0 & & \\
\hline Three-shift & 512 & 5940 & 141 & 2.4 & $2.0-2.8$ & 1.93 & $1.61-2.32$ & $<0.001$ & 1.78 & $1.49-2.14$ & $<0.001$ \\
\hline Two-shift & 293 & 2706 & 121 & 4.5 & $3.7-5.3$ & 3.02 & $2.50-3.66$ & $<0.001$ & 2.62 & $2.17-3.17$ & $<0.001$ \\
\hline \multicolumn{12}{|l|}{$\begin{array}{l}\text { Sub-cohort } 1^{c} \\
(\mathrm{~N}=2319)\end{array}$} \\
\hline Daytime & 2119 & 18649 & 229 & 1.2 & $1.1-1.4$ & 1.0 & & & 1.0 & & \\
\hline Three-shift & 125 & 1248 & 31 & 2.5 & $1.7-3.5$ & 2.64 & $1.80-3.89$ & $<0.001$ & 2.08 & $1.42-3.04$ & $<0.001$ \\
\hline Two-shift & 75 & 635 & 25 & 3.9 & $2.7-5.8$ & 3.89 & $2.54-5.95$ & $<0.001$ & 3.09 & $2.02-4.73$ & $<0.001$ \\
\hline \multicolumn{12}{|l|}{$\begin{array}{l}\text { Sub-cohort } 2^{d} \\
(N=1625)\end{array}$} \\
\hline Daytime & 1515 & 11742 & 93 & 0.8 & $0.6-1.0$ & 1.0 & & & 1.0 & & \\
\hline Three-shift & 69 & 557 & 15 & 2.7 & $1.6-4.5$ & 4.62 & $2.62-9.14$ & $<0.001$ & 3.55 & $2.02-6.25$ & $<0.001$ \\
\hline Two-shift & 41 & 251 & 12 & 4.8 & $2.7-8.4$ & 6.64 & $3.60-12.2$ & $<0.001$ & 4.86 & $2.62-9.01$ & $<0.001$ \\
\hline
\end{tabular}

a $\mathrm{HR}$ adjusted by age, smoking, alcohol drinking, leisure time physical activity, BMI and $\mathrm{HbA1c}$.

o Original cohort; No restriction by BMI.

c Sub-cohort 1; Subjects whose BMI were $20.0-25.0 \mathrm{~kg} / \mathrm{m}^{2}$ during follow up.

d Sub-cohort 2; Subjects whose BMI were $20.0-25.0 \mathrm{~kg} / \mathrm{m}^{2}$ and change in BMI was $<2.5 \mathrm{~kg} / \mathrm{m}^{2}$ during follow up.

results of the Cox proportional hazards model analysis for each cohort. There were two major findings. First, in the original cohort, age-adjusted HR was significantly higher among rotating shift workers than daytime workers [HR 1.93, 95\% confidence interval (95\% CI) $1.61-2.32$, HR $3.02,95 \%$ CI $2.50-3.66$, respectively for 3- and 2-shift workers). Results were not significantly altered even following adjustment for age, BMI, HbA1c at baseline, smoking habit, alcohol consumption, and physical activity during leisure time (HR 1.78, 95\% CI 1.49-2.14 and HR 2.62, 95\% CI 2.17-3.17, respectively). Compared to 3 -shift workers, 2-shift workers were associated with a higher risk for these analyses; the $95 \% \mathrm{CI}$ of the results did not overlap. The age-adjusted HR of 2- compared to 3 -shift workers in the original cohort was $1.45(95 \%$ CI 1.13-1.86; multivariate HR 1.42, 95\% CI 1.11-1.82; data not shown).

Second, the crude incident rate (number of IGT incident per 100 person years) among day workers decreased according to BMI restrictions (from 1.7 for the original cohort to 1.2 for sub-cohort 1 and 0.8 for sub-cohort 2). On the other hand, this trend was not observed for the incident rate among shift workers (2.4, 2.5 , and 2.7, respectively, for 3-shift workers and 4.5, 3.9 , and 4.8, respectively, for 2-shift workers). Following this finding, HR calculated by the Cox proportional hazard model increased according to the BMI restrictions. The restrictions increased the multivariate HR for 3 -shift workers from 1.78 for the original cohort, to 2.08 for sub-cohort 1 and 3.55 for sub-cohort 2; and also for 2-shift workers from 2.62 for the original cohort, to 3.09 for sub-cohort 1 , and 4.865 for sub-cohort 2 .

\section{Discussion}

Survival analysis of 6413 workers with permanent work schedules revealed an increased risk of developing IGT among both 2- and 3-rotating shift workers compared to daytime workers over a follow-up period of 23.2 years (mean follow-up period 9.9 years). Additionally, significant differences in this risk were observed for different types of shift schedules, with 2-shift workers showing a higher risk than 3 -shift workers. Relative risk increases were still observed among subjects without obesity. Daytime workers revealed a decrease in the incidence rate of IGT when we excluded the effects of body weight change during follow-up by restricting subjects, but this did not alter among shift workers.

For the purposes of this study, cases of IGT were defined by $\mathrm{HbAlc}$ and not by fasting blood glucose (FBG) levels. Although a recent study suggested that a combination of FBG and $\mathrm{HbA} 1 \mathrm{c}$ more efficiently determines subsets of individuals at risk from developing diabetes (11), it is difficult to obtain FBG measurements from large numbers of workers, particularly shift workers. HbAlc is thought to be less relevant in screening for IGT or diabetes compared to FBG, however, its measurements are not affected by dietary intake before the examination and are regarded as a practical index 
of average blood glucose levels. Using the JDS standardized method (9), we measured HbAlc and selected a cutoff value for case of $\geq 5.9 \%$ according to the recommendation of the Japan Society of Ningen Dock (8). Compared to the international standard method of National Glycohemoglobin Standardization Program (NGSP), the JDS method reveals a $0.4 \%$ lower value. Thus $5.9 \%$ using the JDS method corresponds to $6.3 \%$ using the NGSP method (9). Had we set a higher threshold value of $>6.1 \%$ ( $6.5 \%$ using the NGSP method) based on the guidelines of the European Association for the Study for Diabetes (12), medical intervention would likely have been required before the endpoint of the study. Thus, the case definition of IGT for this study identified subjects at a relatively early stage that were non-biased for medical intervention.

Previous work suggested that body weight gain is a mediator between shift working and IGT risk (3). However, the results of the present study revealed an increased incidence rate of IGT even among shift workers whose body mass remained normal during the follow-up period, suggesting the likelihood of an additional explanation for the IGT risk among shift workers. Sleep disturbances have often been reported as a risk factor for diabetes (13); furthermore, experimental restriction of sleep to 5.5 hours reduced the glucose tolerance and insulin sensitivity among 11 healthy volunteers (14). As shift workers are also a high risk population for developing sleep disorders (15), a pathway for IGT risk mediated by sleep disturbances is certainly conceivable.

Recently, an experimental mouse study revealed the presence of hyperglycemia and hypoinsulinemia among mice carrying a mutant clock gene (16). Genetic expression of clock genes is known to be disturbed among shift workers (17), suggesting that this may be a factor contributing to the high risk incidence of IGT.

The corporate 3 -shift work analyzed in this study was of a counter-clockwise rotation type, which was previously shown in an intervention study of 45 healthy volunteers to be associated with less sleep and induce higher serum glucose levels compared to clockwise rotation 3 -shift work (18). However, the present study revealed a greater risk of developing IGT among 2- compared to 3 -shift workers, which was consistent with another previous study (2) and the finding that 2-shift workers with longer night shifts are associated with an elevated risk of sleep problems than 3-shift workers (19).

The present study had a number of limitations. First, information regarding lifestyle confounding factors is relatively limited in its number and quality. There were a lot of missing data for these variables but it is difficult to confirm the situation because recording began $>20$ years ago. To take into account the effect of missing values, missing values in lifestyle factors were treated as additional categories in the multivariate analysis but the results did not significantly change. Also, we did not collect information regarding previously reported risk factors of IGT, including dietary habits or patterns, family history of IGT and work stress, so we could not evaluate the effect of these factors. Furthermore, information regarding socioeconomic factors such as type of work or educational level was not collected, and could thus not be evaluated. It was regarded that age at first health check up (ie, baseline) could be a surrogate indicator for educational level because most of the new employees were new graduates in this company. Adjustment for the variable by the Cox proportional hazard model did not alter the result. Second, some selection bias was unavoidable as we excluded those subjects whose work schedules were rearranged during the course of the study. For example, some subjects were moved from shift to daytime work due to shift work-related health problems. We excluded these subjects from the analysis, focusing instead on the "healthy survivors". However, despite this, the risk might be underestimated so the bias would not change the conclusion.

Some unique strengths of our study warrant mention. First, the validity and reliability of exposure information was high because long-term follow-up data regarding work schedules were collected from industrial records. IGT misclassification was also likely to be rare since laboratory testing of blood samples was carried out at annual health check-ups. Second, only subjects with a permanent work schedule were included in the study, removing a bias from the influence of rearranged work schedules. Third, since all study subjects belonged to the same company, the socioeconomic gap is likely to have had relatively little effect on the results, compared to studies conducted among several companies or in the general population.

\section{Concluding remarks}

Both 2- and 3-rotating shift workers were associated with a significantly elevated risk of developing IGT compared to day workers. IGT risk level was also associated with different shift schedules, with 2-shift workers having a higher risk of developing IGT than 3-shift workers. The risk was still observed among workers whose BMI remained normal during the follow-up period, suggesting that, rather than obesity, an alternative explanation such as sleep disturbances is associated with IGT risk.

\section{Acknowledgement}

The authors express their sincere appreciation to the corporation that participated in this study. The authors 
would also like to thank Mr Hiroyuki Kanaoka. Without his support, our research project could not have been launched.

This work was financially supported by KAKENHI Grants-in-Aid for Scientific Research (Nos. 19790437 and 22590618) from the Ministry of Education, Culture, Sports, Science and Technology, Japan, and by a Research Grant for Occupational Health 2007-2008 from the Occupational Health Promotion Foundation, Japan. The authors declare that they have no competing financial interests.

\section{References}

1. International Agency for Research on Cancer (IARC). IARC monographs on the evaluation of carcinogenic risks to humans. Lyon: IARC; 2006.

2. Morikawa Y, Nakagawa H, Miura K, Soyama Y, Ishizaki M, Kido T, et al. Shift work and the risk of diabetes mellitus among Japanese male factory workers. Scand J Work Environ Health. 2005;31:179-83. http://dx.doi.org/10.5271/ sjweh.867.

3. Kroenke CH, Spiegelman D, Manson J, Schernhammer ES, Colditz GA, Kawachi I. Work characteristics and incidence of type 2 diabetes in women. Am J Epidemiol. 2007;165:175-83. http://dx.doi.org/10.1093/aje/kwj355.

4. Suwazono Y, Sakata K, Okubo Y, Harada H, Oishi M, Kobayashi E, et al. Long-term longitudinal study on the relationship between alternating shift work and the onset of diabetes mellitus in male Japanese workers. J Occup Environ Med. 2006;48:455-61. http://dx.doi.org/10.1097/01. jom.0000214355.69182.fa.

5. Karlsson B, Alfredsson L, Knutsson A, Andersson E, Toren K. Total mortality and cause-specific mortality of Swedish shiftand dayworkers in the pulp and paper industry in 1952-2001. Scand J Work Environ Health. 2005;31:30-5. http://dx.doi. org/10.5271/sjweh.845.

6. Stevens RG, Hansen J, Costa G, Haus E, Kauppinen T, Aronson KJ, et al. Considerations of circadian impact for defining 'shift work' in cancer studies: IARC Working Group Report. Occup Environ Med. 2011;68:154-62. http://dx.doi. org/10.1136/oem.2009.053512.

7. Kubo T, Oyama I, Nakamura T, Shirane K, Otsuka H, Kunimoto M, et al. Retrospective cohort study of the risk of obesity among shift workers: findings from the Industry-based Shift Workers' Health study, Japan. Occup Environ Med. 2011;68:327-31. http://dx.doi.org/10.1136/ oem.2009.054445.

8. Japan Society of Ningen Dock. Guideline for assessment of health screening results and ex-post health guidance. Health
Medicine. 2002;17:124-40.

9. Weykamp C, John W. G., Mosca A. A review of the challenge in measuring hemoglobin A1c. 2009; 3:439-45.

10. Sakurai M, Miura K, Takamura T, Ishizaki M, Morikawa Y, Nakamura K, et al. J-shaped relationship between waist circumference and subsequent risk for Type 2 diabetes: an 8-year follow-up of relatively lean Japanese individuals. Diabet Med. 2009;26:753-9. http://dx.doi.org/10.1111/ j.1464-5491.2009.02773.x.

11. Heianza Y, Hara S, Arase Y, Saito K, Fujiwara K, Tsuji H, et al. HbA1c 5.7-6.4\% and impaired fasting plasma glucose for diagnosis of prediabetes and risk of progression to diabetes in Japan (TOPICS 3): a longitudinal cohort study. Lancet. 2011;378:147-55. http://dx.doi.org/10.1016/S01406736(11)60472-8.

12. Ryden L, Standl E, Bartnik M, Van den Berghe G, Betteridge $\mathrm{J}$, de Boer MJ, et al. Guidelines on diabetes, pre-diabetes, and cardiovascular diseases: executive summary. The Task Force on Diabetes and Cardiovascular Diseases of the European Society of Cardiology (ESC) and of the European Association for the Study of Diabetes (EASD). Eur Heart J. 2007;28:88136

13. Cappuccio FP, D'Elia L, Strazzullo P, Miller MA. Quantity and quality of sleep and incidence of type 2 diabetes: a systematic review and meta-analysis. Diabetes Care. 2010;33:414-20. http://dx.doi.org/10.2337/dc09-1124.

14. Nedeltcheva AV, Kessler L, Imperial J, Penev PD. Exposure to recurrent sleep restriction in the setting of high caloric intake and physical inactivity results in increased insulin resistance and reduced glucose tolerance. J Clin Endocrinol Metab. 2009;94:3242-50. http://dx.doi.org/10.1210/jc.2009-0483.

15. Akerstedt T. Shift work and disturbed sleep/wakefulness. Occup Med (Lond). 2003;53:89-94. http://dx.doi. org/10.1093/occmed/kqg046.

16. Turek FW, Joshu C, Kohsaka A, Lin E, Ivanova G, McDearmon E, et al. Obesity and metabolic syndrome in circadian Clock mutant mice. Science. 2005;308:1043-5. http://dx.doi.org/10.1126/science. 1108750 .

17. Akashi M, Soma H, Yamamoto T, Tsugitomi A, Yamashita S, Nishida E, et al. Noninvasive method for assessing the human circadian clock using hair follicle cells. Proc Natl Acad Sci U S A. 2010;107:15643-8. http://dx.doi.org/10.1073/ pnas. 1003878107.

18. Orth-Gomer K. Intervention on coronary risk factors by adapting a shift work schedule to biologic rhythmicity. Psychosom Med. 1983;45:407-15.

19. Takahashi M, Iwakiri K, Sotoyama M, Higuchi S, Kiguchi M, Hirata M, et al. Work schedule differences in sleep problems of nursing home caregivers. Appl Ergon. 2008;39:597-604. http://dx.doi.org/10.1016/j.apergo.2008.01.003.

Received for publication: 11 November 2011 